\title{
PENSAR A TRADUÇÃO E O FEMINISMO NEGRO - ENTREVISTA COM OCHY CURIEL ${ }^{1}$
}

\author{
Dennys Silva-Reis [DSR]: Tem alguma experiência com a prática de tradução \\ feminista?
}

Ochy Curiel [OC]: Sim. Com Jules Falquet traduzimos as contribuições das feministas materialistas francesas Colette Guillaumin, Paola Tabet e Nicole Claude Mathieu, condensadas no texto El Patriarcado al desnudo, tres feministas materialistas, que saiu publicadonoano 2005através da editora independente Brecha Lésbica. Posteriormente, o Grupo Latinoamericano de Formación y Acción Feminista (GLEFAS), coletivo de que faço parte, traduziu o texto "La invención de las mujeres. Una perspectiva africana sobre los discursos occidentales del género” da nigeriana Oyèróké Oyewùmí em 2017, através da nossa editora, também independente, en la frontera.

\section{[DSR]: Acredita que a profissão de tradutora e intérprete é sexualizada? Quais seriam as causas e as consequências disso?}

[OC]: Como se passa em toda a sociedade ocidental, as relações sociais são geralmente sexistas, racistas e classistas. Tem a ver com as hierarquias que se foram construindo desde os inícios da colonização e que continuam na colonialidade contemporânea, e a tradução não escapa disso. Faz parte do sistema moderno/colonial. Os conhecimentos mais valorizados são os produzidos por homens brancos com privilégios de classe, embora também por algumas mulheres com esses privilégios. Isso significa que esses conhecimentos também são os valorizados para que sejam reconhecidos em muitas partes do mundo através da tradução que se faz de suas obras.

[DSR]: Em sua opinião, até que ponto a noção de gênero de uma dada cultura pode ser traduzido em outra cultura?

1 Tradução Marcos Bagno (Universidade de Brasília - UnB)

Ochy Curiel

A professora Ochy Curiel,

Nasceu na República Dominicana e, depois de viver no México, no Brasil e na Argentina, vive atualmente na Colômbia. Doutora em Antropologia Social. É docente-pesquisadora da Universidad Javeriana em Bogotá e também consultora independente. É ativista do movimento lésbico-feminista, antirracista, do feminismo autônomo e do feminismo decolonial e também cantautora. É membra do Grupo Latino-americano de Estudos, Formação e Ação Feminista (GLEFAS), da Tremenda Revoltosa, batucada feminista e do Coletivo Globale Bogotá, festival de documentários críticos. Tem várias publicações nas quais mescla raça, sexo, classe, sexualidade e geopolítica. Em sua produção se destaca o livro La nación heterosexual. Análisis del discurso jurídico y el régimen heterosexual desde la antropología de la dominación (2013).

Dennys Silva-Reis

Doutor em Literatura (Universidade de Brasília - UnB). E-mail: reisdennys@gmail.com 
[OC]: Tal como explicou a argentina María Lugones por meio de seu conceito de colonialidade do gênero, o gênero é uma categoria moderna colonial, pois se reconhece o diformismo sexual entre homens e mulheres, desde as experiências de mulheres e homens brancos/as e burgueses/as, portanto, não é universal. Em muitas outras culturas não existe o gênero, nem sequer as categorias de homens e mulheres. Um exemplo disso é o que explica Oyeronke Oyewumi em seu texto "La invención de las mujeres” na sociedade iorubá do sudoeste da Nigéria. $O$ gênero não existia nessas sociedades antes do contato com o Ocidente, foi imposto através da colonização europeia.

\section{[DSR]: Acredita que há uma diferença entre tradução feminina e tradução feminista?}

[OC]: Sem dúvida. O feminino é uma qualidade resultante da diferenciação que traz consigo a heterossexualidade que se assume que as mulheres têm, o que é um erro, pois os homens também podem ter qualidades que se assumem como femininas. Ao final, são cosntruções sociais. Uma tradução feminista implica uma postura política, embora isso também seja problemático porque não existe só um tipo de tradução feminista. Tudo depende de em que corrente do feminismo a tradução se inscreve.

\section{[DRS]: Qual seria a importância da tradução de teorias feministas no mundo contemporâneo?}

[OC]: Creio que muitos feminismos têm contribuído para complexificar as análises das relações sociais. Há feminismos, como o feminismo negro, o feminismo decolonial que permitem contextualizar a situação de grupos que não são afetados somente pelo gênero, mas também pela raça, classe, sexualidade, geopolítica de forma imbricada segundo contextos específicos. A tradução dessas teorias é importante precisamente para não se generalizar nem universalizar as experiências, o que tem sido o erro do feminismo hegemônico, que tem sido branco em suas teorias e contextos e que só toma como centro de análise o gênero desde as experiências das mulheres brancas, geralmente do Norte.

\section{[DSR]: Qual a sua opinião sobre tradução e ativismo (intelectual ou não)?}

[OC]: Creio que é fundamental para poder fortalecer as coalizões transnacionais. Os e as ativistas devemos fazer tradução de obras e propostas que nos ajudem a compreender melhor a complexidade das relações sociais. Considero importante traduzir não só as obras com uma visão crítica do Norte para o Sul, mas do Sul para o Norte. Por exemplo, temos conhecido as produções das feministas afro-norte-americanas porque têm sido mais traduzidas que as que nós afrolatinas e afrocaribenhas temos produzido, e isso se deve ao fato de os Estados Unidos continuarem sendo um centro privilegiado do saber, o que corresponde à geopolítica do conhecimento, ainda que parta de grupos 
subalternos. É preciso que conheçam nossas propostas no Norte, como uma forma de descolonizar o saber.

[DSR]: A circulação de ideias feministas por meio de tradução incentiva a emancipação de outros grupos de mulheres?

[OC]: Sem dúvida. E não só de mulheres, mas de outros grupos subalternizados. Na medida em que conhecemos as experiências de outros grupos em muitas latitudes, isso ajuda a ter uma compreensão melhor das experiências diversas, e também das lutas e resistências que se fazem em muitos lugares, o que contribui para a coalização transnacional, como disse antes.

[DSR]: Concorda que só mulheres brancas podem traduzir mulheres brancas e só mulheres negras podem traduzir mulheres negras?

[OC]: Não. Considero que, embora nós mulheres negras devamos fazer mais traduções de outras mulheres negras, não se trata de essencializar este exercício. Existem pensamentos, teorias, conceitos tanto de mulheres negras e mulheres brancas que são críticos e interessantes para nossos projetos políticos e que é importante traduzir. O que creio é que as mulheres brancas têm maior acesso e privilégio e muitas vezes tomam as experiências das mulheres negras como meros testemunhos ou matérias primas para seus créditos acadêmicos, por isso é importante que as mulheres afrodescendentes e indígenas façamos tradução da produção de nossa companheiras para evitar a utilização e a instrumentalização de nossas experiências e pensamentos.

[DSR]: Acredita que homens (feministas ou não) são sensíveis e estão aptos para traduzir textos femininos e feministas? Quais seriam os desafios e as potencialidades envolvidas neste caso?

[OC]: Minha resposta a esta pergunta é semelhante à da pergunta anterior. Depende de quais homens. Há homens que tem privilégios de raça, classe, sexualidade, geopolítico, mas há outros que não, como a maioria dos homens de origem africana e indígena de nosso continente, e nesse sentido podem ser nossos aliados, sobretudo se tiverem posições políticas parecidas às nossas. $\mathrm{O}$ importante é saber qual é a intensão da tradução que eles têm.

[DSR]: Existiriam, em sua opinião, agendas feministas compatíveis com estruturas de publicação editorial? Como se poderia buscar uma igualdade de gênero neste campo?

[OC]: Creio que existem políticas editoriais feministas diversas. Não há uma só linha editorial e não creio que todas se limitem a buscar a igualdade de gênero. Há propostas 
feministas que são antirracistas, decoloniais, como existem outras, diria que a maioria, que não são.

[DSR]: Na história da tradução são poucas as tradutoras e intérpretes mulheres conhecidas, sobretudo negras? Conhece alguns nomes? Poderia nos falar sobre elas?

[OC]: Creio que há muito poucas, sobretudo negras e africanas. Aquelas que temos feito traduções, fazemos desde o ativismo, não como parte de um exercício profissional.

[DSR]: Haveria por acaso, em sua opinião, uma "culpa da tradução" por haver mais teoria feminista branca difundida no mundo?

[OC]: Creio que não se trata de "culpa da tradução", mas das possibilidades e do acesso. A maioria das mulheres negras, afros, indígenas de nosso continente não têm suficiente dinheiro, nem tempo, para priorizar a tradução de textos. Também não existem muitas editoras interessadas em traduzir suas obras. Acredito, bem mais, que é uma questão estrutural que tem a ver com a colonialidade do saber, embora, felizmente, cada vez mais algumas de nós entendem a importância de traduzir textos das pessoas negras e indígenas para dar a conhecer seus pensamentos e lutas.

[DSR]: A tradução pode contribuir para a renovação da literatura canônica feminista nas diferentes áreas das ciências humanas?

[OC]:Sem dúvida. Sobretudo se forem traduções das obras das pessoas subalternizadas. É o que vai contribuir para decolonizar o saber feminista e das ciências humanas em nível geral.

[DSR]: Conhece projetos de tradução feminista não hegemônicos? Em caso afirmativo, poderia nos dizer quais e como funcionam?

[OC]: Um deles é o que estamos fazendo no GLEFAS, a partir de nossa editora en la frontera, o que tem feito Brecha Lésbica. As duas são editoras independentes.

[DSR]: Que conselhos daria para uma linguagem (tradutória) menos sexista?

[OC]: Buscar maneiras de escrita que não reflitam a ideologia da diferença sexual, o binarismo de gênero, mas também é preciso fazer isso desde uma postura pós-colonial, o que significa evitar categorias, conceitos, palavras racistas, coloniais, heterossexuais e sobretudo que seja uma tradução apegada aos significados de quem produz e não uma substituição de palavras e conceitos ocidentais. A linguagem também é política.

[DSR]: Qual seria uma boa metáfora para a tradução feminista (negra)? 
[OC]: A amefricanidade de Lélia Gonzalez.

[DSR]: É possível ensinar a traduzir o feminino ou a fazer uma tradução feminista?

[OC]: Sim, mas tudo depende de que tipo de feminismo. Nem todos são iguais, e uma tradução pode ser feminista, mas pode ser bastante racista. Creio que é possível desenvolver metodologias que permitam uma tradução decolonial. 